\title{
Horses and worthwhile causes: Exploring equine-assisted learning at Dune Lakes Horse Inspired Learning Centre in Aotearoa New Zealand
}

\author{
Ricarda Lietz ${ }^{1}$ and Ksenija Napan ${ }^{2}$
}

${ }^{1}$ Healthcare New Zealand

${ }^{2}$ Massey University,

Aotearoa New Zealand
AOTEAROA

NEW ZEALAND SOCIAL WORK 32(4), 40-54.

CORRESPONDENCE TO: Ksenija Napan K.Napan@massey.ac.nz

\begin{abstract}
INTRODUCTION: Equine-assisted therapies and trauma-informed interventions have become increasingly popular with a growing literature suggesting that people can deeply relate to experiential work with horses, where silence, emotional growth, reflection and acceptance are prioritised over talking about problems.

APPROACH: This research, undertaken at a rural learning and retreat centre near Auckland in Aotearoa New Zealand, examines how practitioners tailor equine-assisted interventions (EAI) and sheds light into values, theories and frameworks that underpin their work. The study is based on personal and professional experiences of four practitioners who engage in equineassisted learning.
\end{abstract}

FINDINGS AND APPLICATION: Findings are drawn from the thematic analysis of the transcripts of four semi-structured interviews, highlighting the process of facilitating posttraumatic growth in a professional, supportive and client-centred environment involving a facilitator, a horse, and a person keen to improve the quality of their life. Application of this modality, particularly when working with clients with complex trauma, is explored with a special emphasis on the relevance of involvement of animals in social work practice.

KEYWORDS: Horse-assisted learning; horse-assisted intervention; animals in social work

\section{The context}

Located close to the Auckland's NorthWest Coast and adjacent to Lake Kereta and Woodhill Forest's ancient sandhills, Dune Lakes Retreat and Equine Centre is situated at the South Kaipara Head Peninsula in Aotearoa New Zealand. It is a learning and retreat centre which offers programmes, workshops and interventions for individuals, groups and organisations, as well as school holiday programmes, team building and trauma work, programmes for youth in conflict with the law and workshops focused on prevention and building connections. Dune Lakes Retreat and Equine Centre's registered charity, Equine Pathfinders Foundation, was created with the mission to make equine-assisted learning and growth possible to all and to improve wellbeing of children, youth, adults and families as well as the wider community. The Equine Pathfinders Foundation accepts referrals and offers a diverse range of programmes throughout the year. Courses for young people include life skills training, holiday camps, interactive experiences with 
horses for youth, particularly suitable for youth-at-risk, where connection to others can be learned through practising caring and appropriate life skills, as well as adventure-based experiences for young people. Programmes assisting individuals and families include teaching respect, loyalty, horsemanship skills, boundaries and resilience but also mutual support and empowerment, enabling inclusion, healthy and fulfilled relationships, healing and trauma recovery. These courses often attract people with lived experience of abuse or violence as well as people recovering from addictions. Personal discovery retreats allow participants to integrate nature, movement and meditation or to learn dealing with problematic behaviour or anger issues by spending time with horses, in a group, and in self-reflection. The centre's workshops offer corporate team building, leadership and self-awareness trainings as well as annual festivals and special retreats (Dune Lakes Lodge, 2015).

Dune Lakes works from the premise of horses being engaged at liberty with humans, meaning they are never forced to interact and are free to leave the interaction at any point. This principle extends to all participants. Underpinned by such a non-oppressive framework, a detailed and descriptive approach in this research was taken in order to gain in-depth insights about the process of EAI, allowing practitioners' voices to be heard.

\section{Authors' intentions}

Author 1: I have carried out this research from the perspective of a social worker and a survivor. The aim was to understand the overarching frameworks equine-assisted intervention (EAI) practitioners use for their work and if those could be useful in social work practice. Having experienced childhood trauma, I found comfort and soothing in my relationship with horses, without having been aware of the underlying therapeutic effects that had a significant impact on my wellbeing. I wondered if having a practitioner alongside would have been even more beneficial. A curiosity about how and why the magical learning and healing processes unfolded in my past and how similar processes may benefit my clients, enabled me to explore ways how this modality can be used in social work practice. Targeting emotional, psychological and mental health challenges is a relatively new way of utilising a horse's presence. Viewing this research through a social work lens, I wondered if horses might be perfect to assist social work clientele experiencing complex trauma and my intention was to explore the horse-practitioner-client triangle interaction as a whole rather than presenting a snapshot.

Author 2: I always felt deeply connected to animals. Most of my peak experiences involved animals, I learned how to be a parent through my dogs, and they influenced my decision to have children and become a social worker. Swimming with wild dolphins gave me insights and experiences I could never imagine. Experiencing "join up" and "belly button" riding at Dune Lakes, "holding space" with horses and lying down next to the fully relaxed horse lying on his side enabled me to transcend the mundane, discover who I really am and relate to the world in a more connected and appreciative way.

This research is a part one of a wider ongoing study about humans, interspecies communication and particularly horses and their relationship with us. It focusses on EAI practitioners' views on the process and content of their sessions. The second part of a larger inquiry that is in process now, focuses on benefits for clients and the third part (I am still looking for a most appropriate methodology for this), will focus on horses themselves in order to discover what is there for them and why do they engage in relationships with humans.

\section{The purpose, aim, intention and study design}

The purpose of this study was to look at the process of EAI at Dune Lakes Lodge by 
exploring practitioners' views on the horsepractitioner-client triadic relationship and how it affects their wellbeing. The aim was also to gain a deeper understanding of what EAI consists of in the context of social work and how healing of complex trauma can be facilitated. The universal term, EAI, is used in order to include all interventions in which interactions with horses assist humans in encouraging personal and post-traumatic growth as well as in overall well-being or acquisition of new skills and abilities. A qualitative, interpretative research design using semi-structured interviews best suited this purpose. Four experienced practitioners have been interviewed; all interviews were transcribed and thematically analysed in order to outline the process and the content of the sessions and their effectiveness from practitioners' viewpoints.

\section{Literature review}

The literature review focusses on EAI as a learning and therapeutic approach, excluding other animal-assisted therapies and modalities that involve horses, such as riding for people with a physical disability or pet therapies.

A number of articles about horse-assisted learning and therapy from practitioner and client perspectives were reviewed and analysed (Trotter, Chandler, GoodwinBond, \& Casey, 2008; Dunlop \& Tsantefski, 2017; Johanson, Wang, \& Binder, 2016; Szczygiel, 2018; Schroeder, \& Strout, 2015; Tuuvas, Carlsson, \& Norbert, 2017). Meaningful, educative and multilayered information was found in several research articles and books where horses are involved and where humans feel that they facilitate the process of learning and personal growth on an experiential level (Brandt, 2004; Buck, Bean, \& Marco, 2017; Lee \& Makela, 2018; Yatchmenoff \& Sundborg, 2017). Research suggests that a variety of beneficial EAI pathways are available. EAI can be useful for young people who experience difficulties with transitioning into adulthood
(Waite \& Bourke, 2013), children and adolescents who are at high risk of social or academic failure (Frederick, Hatz, \& Lanning, 2015; Trotter et al.,2008), children and youth experiencing problematic parental substance abuse (Dunlop \& Tsantefski, 2017) and for people with a history of substance abuse (Adams et al., 2015; Kern-Godal, Brenna, Arnevik, \& Ravndal, 2016). EAI proved to be helpful for adolescents who deliberately selfharm (Carlsson, 2017) and children and youth with psychosocial and behavioural difficulties, post-traumatic stress symptoms and complex trauma (Buck et al., 2017; Mueller \& McCullough, 2017 Naste et al., 2017). EAI can facilitate general psychological improvement and address unexpressed feelings and unresolved conflicts from the past which are still causing psychological distress in the present (Klontz, Bivens, Leinart, \& Klontz, 2007) and attachment issues (Carlsson, 2017; Naste et al., 2017). Therapeutic work with horses showed improved social attitudes and skills as a result of reduced cortisone hormone stress levels and increased oxytocin levels in people with autism, alleviating their stress responses (Sanchez, Castro, Herrera, \& Juanez, 2014).

Trauma-informed interventions are becoming increasingly popular in the field of psychotherapy, counselling and social work (Albright, 2018). Schroeder and Strout (2015) found that EAI group work with trauma survivors who were struggling with post-traumatic stress helped to increase confidence and develop meaningful and trusting relationships. The benefits of building a bond and a relationship based on trust and mutual respect as well as the importance of the connection to nature are sufficiently described and in agreement with research completed in the last few years (Burgon, Gammage, \& Hebden, 2018; Carlsson, 2017; Naste et al., 2017; Sullivan, 2014; Tuuvas et al., 2017). The relationship between trauma-informed social work and EAI indicates that horse-assisted therapeutic interventions offer support and learning 
for clients who have experienced trauma in the past or currently have emotional, mental or social problems. The recognition of the experience of past or current trauma, the provision of trauma-informed care as well as a safe relational environment are also essential for empowering social work practice, as Yatchmenoff and Sundborg (2017) and Szczygiel (2018) have claimed.

Horses are social animals. Their high state of awareness and their use of body language facilitates human-horse communication and plays a major role in working with horses (Brandt, 2004; Buck et al., 2017). This seems particularly important from a survivor perspective and in the context of trauma. Humans can deeply relate to non-talking horse therapy where silence, emotional growth and acceptance is supported (Albright, 2018; Buck et al., 2017; Waite \& Bourke, 2013). By mirroring the client's emotions, the horse responds to the client in a reflective way, which then can be identified by the facilitator, social worker or a therapist and utilised for growth or transformation. Increased control over one's own life, as well as a growing confidence in one's own ability to cope with life's circumstances can be developed through the direct feedback given by a horse and a facilitator. The learned information can then be applied to personal present and future challenges (Albright, 2018; Buck et al., 2017; Carlsson, 2017; Waite \& Bourke, 2013). Lee and Makela (2018) also emphasised the importance of the minimal but skilled input by a highly trained practitioner and recommended further exploration of EAI in therapeutic settings by integrating interdisciplinary perspectives. This recommendation influenced us to further explore the field of the experimental, yet skilled work of EAI practitioners.

The influence of particular settings to clients' healing processes is also discussed in the literature. Significant for clients' increased wellbeing is a rural and tranquil environment (Kern-Godal et al., 2016; Hamilton, 2011; Mueller \& McCullough, 2017). A rural environment can be experienced as less threatening and the absence of stigma, often attached to clinical places, is calming (Brandt, 2004), especially in a social work context, where children and youth have been involved with numerous social services in the past (Albright, 2018; Donaghy, 2006; Kern-Godal et al., 2016). "When services feel safe, empowering, and welcoming for those affected by trauma, service recipients are more likely to engage and benefit from care" (Yatchmenoff \& Sundborg, 2017, p. 167).

Limited research is available on how therapeutic work with horses can be utilised to a greater extent as an effective mental health and wellbeing tool by social services (Lee \& Makela, 2018) and this project aims to provide more insight into this field of practice. Literature covers the importance of the setting, positive aspects of the idea to replace talk-therapy with non-verbal concepts as well as the general positive achievements of EAI in the context of complex trauma which impacts the lives of social work service users. Literature suggests that more research exploring the importance of the practitioner's professional background knowledge would be beneficial in order to prove that more than a horse and a paddock is required to support clients on their healing journey (Anestis, Anestis, Zawilinski, Hopkins, \& Lilienfeld, 2014; Buck et al., 2017; Dunlop \& Tsantefski, 2017).

\section{Identifying shortcomings and gaps in EAI literature}

Research about psychotherapeutic and social work theory and practice with horses is often limited to links between investigated therapeutic interventions and a specific group of clients (Naste et al., 2017). Research providing more detailed descriptions of how exactly EAI expert knowledge, skills and expertise is applied in practice would be beneficial (Anestis et al., 2014; Buck et al., 2017; Dunlop \& Tsantefski, 2017). Limited research is also available on how the therapeutic work of EAI can be utilised to a greater extent as an effective mental health and wellbeing tool by 
social services (Lee \& Makela, 2018) and this project aims to provide more insight into this field of practice. The decision to use the term EAI was based on the definitional difficulties outlined in the literature and the fact that the exact intervention used by individual participants was unknown until the selection was established.

Existing literature covers a wide range of possibilities in the area of EAI, being predominantly qualitative studies.

Effectiveness (assessed by an in-depth analysis essential for qualitative research, in this case, as perceived by practitioners) is investigated providing findings that support the importance of safety and bonding in the relationship with the horse. The unassuming presence of a horse allows clients to open up and communicate freely, allowing unexpected insights to emerge. Further literature covers the importance of the setting, positive aspects of the idea to replace talk-therapy with non-verbal concepts as well as the general positive achievements of EAI in the context of complex trauma (Wamser-Nanney \& Vandenberg, 2013). This, however, has also been found to be an area which may benefit from more research where light can be shed into increased opportunities for greater utilisation in social work.

\section{Research design, ethical considerations and data analysis}

A qualitative, interpretative research methodology was used in order to allow a detailed description of the elements of EAI and its relevance for social work. The goal was to allow a deeper understanding of EAI and its effectiveness. A bottom-up inductive research approach has been taken as the study has progressed from findings into thematic coding and interpretation and progressing into generating clarification and new insights (Smith \& Osborn, 2003; Tolich \& Davidson, 2011).

The four participants were professionals trained in EAI, who work in Aotearoa
New Zealand and who have offered EAI services at Dune Lakes Lodge for a minimum of five years. Participants had insight and knowledge about what social work consists of in the Aotearoa New Zealand context and which social services are available.

Semi-structured interviews allowed for a wide and comprehensive variety of answers. An analysis of the interviews was conducted, allowing patterns and key themes from within the data to become actively identified. The researcher was aware of the possibility for these themes to be influenced by her own position and a thematic analysis process offered insight into meaningful patterns while establishing a systematic and organised approach (Braun \& Clarke, 2012; Garden \& Kabacoff, 2011). By analysing and coding qualitative data in a systematic manner, generic codes were established linking themes to broader issues (Braun \& Clarke, 2012). Themes showed patterns in the data that connect to the research question and provided meaning (Braun \& Clarke, 2006). Codes and categories were generated, themes and sub-themes grouped accordingly and set aside before beginning with the next transcript. Finally, the selected themes and quotes were written up and interpreted in a light of the research question which led to a deeper understanding of the findings.

Ethical approval was granted by Massey University Human Ethics Committee under the number 4000019422 for research entitled: "Exploring equine-assisted learning and therapy in the context of trauma-informed care and its relevance for social work in New Zealand". ${ }^{\text {. }}$

Qualitative studies need to be conducted with the "right" ethical attitude (Merriam, 2002) so critical reflection of our own positions ensured that our own biases and worldviews have not influenced our investigation and we were fully aware how our love for horses can blind us. Ethical dilemmas had been considered and discussed beforehand to ensure ethical safety for participants involved. Full information 
about the purpose of the study before starting each interview was revealed, the participants understood that they could withdraw from participating in the study at any time and written consents were signed before interviews commenced.

During the process, the Code of Ethics/ Ngā Tikanga Matatika (ANZASW, 2019) was respected and participants were professionals trained in therapeutic client care. In the unlikely case that the interview may have triggered traumatic memories or other disturbing images, all would have been able to contact their supervisors. The interviewer made sure that she had a person at hand with whom she could talk to in case the interviews triggered negative emotions. All participants, documents and the environment were treated in respectful ways. The participants did not have access to their colleagues' interviews but were given their own full transcripts before agreeing for the report to be published. Participants granted their consent to use their full names in this publication and have been given a final draft of this article for approval.

\section{Participants}

Rosemary Wyndham-Jones is the owner of Dune Lakes Lodge and founder of the charitable organisation Equine Pathfinders Foundation. Her journey with horses started approximately 25 years ago with a yearlong horsemanship training in Wales where she worked with a woman who taught her how horses communicate with each other. Extensive training and certificates followed, such as the Equine-Assisted Growth and Learning Association (EAGALA) training and modules with the Gestalt Equine Institute. She is a natural horse-friendship trainer, an EPONAQUEST Riding Focused Instructor and qualified with Hiltrud Strasser in Holistic Hoof-Care Management.

At the time of this research, Alistair Wait worked alongside Rosemary at Dune Lakes Lodge. He has conducted business consultations and educational programmes in the private and governmental sector and has more than 20 years of experience as a Certified Master Trainer in Neurolinguistic Programming (NLP), facilitating transformational learning. He has also trained extensively in EAL under the EAGALA model and is an accredited trainer in Spiral Dynamics Integral.

Geraldine Keith is a clinical psychologist in practice for over 40 years in Wellington, providing consultancy, assessment, and therapeutic interventions. She also is a certified professional in EAL and psychotherapy under the EAGALA model, has completed two training modules of the Gestalt Equine Institute of the Rockies (GEIR) and offers workshops at Dune Lakes Lodge.

Rob Pliskin is from the United States, has Masters degrees in Social Work and Education. He advocated for American wild horses in the 1970s and had worked since 2003 as an EAGALA Advanced Dual Certified Equine Specialist and mental health professional through the gestalt therapy lens. Rob has supported children, youth and adults in northern Israel, Aotearoa New Zealand and the Appalachian Counties of Ohio.

All participants were qualified and experienced practitioners in therapy, social work and horsemanship with minimum of 10 years of expertise in these endeavours.

\section{Identified themes and findings}

This section presents the findings from the collected data. Five key themes have been identified. The first highlighted the importance of the context, including choice, inclusiveness as well as the client's physical and emotional safety. The second theme explored social work values, such as non-judgmental attitudes, being strengthsfocused and client-centred. The third focusses on the role of the practitioner as a knowledgeable guide, exploring the particular knowledge, values and skills required in this practice modality. The fourth theme explores the importance of holding 


\section{QUALITATIVE RESEARCH}

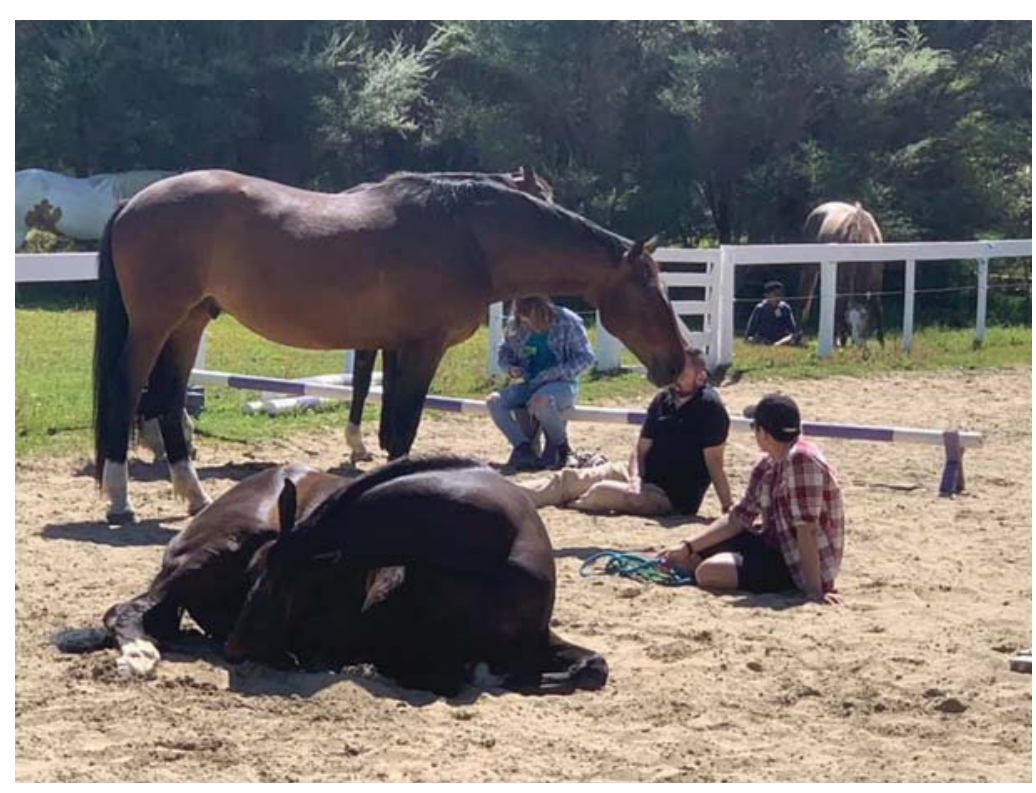

Holding space with horses. horses in a herd and giving them a choice about whether they want to communicate with humans or not, is essential:

I much prefer to do what I do with horses that is being at complete liberty, so that they are actually not restricted in any way, so that they have a choice whether they want to be with you or not.

Alistair explained that the intervention starts before people's arrival and ends long after:

One of the things I think that makes a huge difference with the boys and the young offenders that are coming out is that when they arrive, we'll sit around the table and have lunch with them.

Rob confirmed the importance of taking the time to be welcoming, kind and inviting for participants to engage in shared activities. He mentioned that all that is part of the intervention.

\section{Theme 2: Compatibility with social work values}

Participants agreed that strength-focused practice and a high degree of being personcentred and supportive is essential for people to recognise their own strengths and find their own answers. Part of a holistic approach is also the awareness that EAI can be a spiritual process, highlighted Rosemary, and Geraldine confirmed that:

Out of it can come a greater sense of purpose in life, a greater sense of spiritual connections, a greater sense of new possibilities.

And all I feel I do is like hold, hold the space for that to happen. [...] The horses give the learning experience.

Participants agreed that their personal and unique experience with the horse is paramount and Geraldine added that a sense of respect, concern and consideration for the horse must also be part of the environment's role. Rosemary agreed that keeping the share values and principles, but differ in the methods practitioners use. It seems that EAI practitioners blurred these divisions and worked with clients utilising techniques that suited their clients. Participants agreed that being a provider of therapy through the lens of trauma-informed care is essential in order to respond to traumatic experiences.
Counselling, psychotherapy and social work 
There was a strong view of benefits of the strengths perspective in practice and a belief in post-traumatic growth. They all claimed that everyone has their own individual experiences based on who they are, and the process should be non-directive, as Alistair outlined:

Horses are interested in who a person is right now, regardless of their upbringing or what happened in the past, which includes them as equal participants in a perfect therapeutic alliance in social work contexts. It allows people to trust and confide in a horse and tell them a story.

Alistair reflected here on the principles of safety, trust, collaboration, choice and empowerment which are of importance for social work practice. Geraldine deepened that thought by stating:

It's just simply being, sensing, reacting, noticing. A completely non-judgmental, objective observer.

Both Rob and Alistair noted that people create their own inner, subjective experience, based on the horse's and the practitioner's non-judgmental input. The communication of a positive and non-judgmental attitude and the unconditional acceptance of others are social work values in action.

Geraldine confirmed that the practitioner provides guidance only, however, practitioner's knowledge and expertise are essential:

I think one important thing to be good at is getting out of your own way and actually... quit being the expert. [...] It's your duty to know as much as you do know to help the person figure out what they need to figure out. But you must have a really astute sense of how important it is to be in the background as much as possible because the magic happens between the horse and the client.

Integrating an understanding of people and their situations, compassion, warmth and a non-judgmental attitude into practice allows the practitioner to value and validate a person and professionally respond to client needs, thereby fully engaging in interpersonal social work skills (Trevithick, 2008), yet in a very discreet way.

\section{Theme 3: The knowledgeable guide on the side}

Interacting with a large and powerful animal can create an opportunity for the client to overcome personal fears and to regulate emotions. The ability and willingness to go on a transformative journey with the client must be at the centre of the practitioner's role, supported by sound theoretical knowledge, professional frameworks and individual approaches.

Participants confirmed that a sound professional background allows choice between whatever is needed in the moment and negotiate it with the client. Gestalt, as a therapeutic modality, has informed and shaped Geraldine, Rosemary and Rob's practice in seeking to understand trauma and how to work with it and promote posttraumatic growth.

Neurolinguistic programming (NLP) provides the framework for Alistair in doing transformative work and his practice is also informed by mindfulness and yoga practice. Rob offers eye movement desensitisation and reprocessing (EMDR) sessions for clients with complex trauma and combines them with EAI as this can enhance the healing process (Shapiro, 2017). Rob, who on top of his social work degree, is educated in cognitive behaviour therapy (CBT) and dialectical behaviour therapy (DBT), finds gestalt and the EAGALA learning (being holistic and allowing to view a person in the context) most relevant in his work.

Geraldine, as a registered psychologist, uses constructed activities, such as the trauma acceptance ally in her psychotherapeutic, trauma-informed work, which allows her 
to address client trauma based on evidencebased practice. Rosemary incorporates breathing techniques, mindfulness, horsemanship skills and brings her many years of personal experience in order to expand client learning on a spiritual level as well by focusing on meditative practices during a session.

Sound professional knowledge as well as the ability to provide the right guidance at the right moment contributes to the meaningful EAI practice.

\section{Theme 4: Holding space for transformational, long-lasting change}

Participants indicated that EAI's beneficial effects are suitable for most people. However, Alistair and Rosemary have found in their practice that particularly people who have experienced complex trauma or who did not receive the help they needed in other therapies, such as talk-therapies or medication, can benefit from EAI. Alistair highlighted:

A lot of the children are burned out with talk therapy where the client is reliving the past over and over again. And so is the pre-preposition that goes with that: the past is always going to be there.

All participants highlighted the importance of non-verbal communication in the context of EAI and trauma (van der Kolk, 2002). Talking about personal trauma can be part of the transformational process, but as Rosemary, Alistair and Rob pointed out, because EAI is about the present moment, telling the story is not necessarily required. Rosemary explained that encouragement to share feelings with the horse, for example, can be a more powerful tool:

I just say to them, whatever is going on for you, just go and tell the horse [...] They tell it out loud or they normally tell it to the horse in their head. [Or] I ask what message the horse may have for you? Of course, it's themselves talking to themselves [laughs], but it's always very powerful. [...] Like, within fifteen minutes they are like, they've got this different look on their face, and they are like smiling, they are happy.

Participants agreed that this process allows change of perception to be achieved within minutes, opening pathways to change in behaviour with a minimum of guidance, and free of over-interpretation. This makes EAI a powerful and robust tool, with a possibility of fast and long-lasting results. Geraldine explained:

In terms of a systems theory, you only have to change one thing for a whole lot of other things to change. And the horse, the relationship a horse offers to a person and what they discover in terms of their patterns of approach, avoidance, intimacy, trust [can reveal that] sometimes the horses are the greatest teachers.

Participants also identified that EAI shifts the focus away from the person to the horse. People can talk about a horse and will often unconsciously refer to their own feelings, projecting these feelings onto the horse, as Rosemary explained:

That allows people that are shut down to open up because they [did not have] to talk about themselves. They can talk about the horses.

Rosemary added that for the practitioner holding the space is often all that is necessary in order to give a meaningful learning experience and to enable personal growth. Part of a holistic approach is also the awareness that EAI can be a spiritual, even sacred, process, highlighted Rosemary. She demonstrated how profound "a safe space" can be experienced:

And I just got [the group] into holding that sacred space and they all where probably there for about half an hour, just sitting or laying, or just being there 
with the horses. [...] It was like a ... you know, I am not religious, but it was almost like I went into a church or going into a very special place. It was like, it was very sacred. And all I feel I do is like hold, hold the space for that to happen. So, yeah. I take them into that very space because often they don't spend enough time in that space.

The process is simple, but not simplistic, confirmed Alistair and Geraldine, as much of the learning is simply created by the practitioner's guidance through observation and feedback.

\section{Theme 5: The horse's role in a therapeutic alliance}

Relational aspects, such as the horse offering communication and companionship, have been found central to positive achievements. Rob commented:

Horses are highly relational, they are completely social animals [...] They are prey animals, they live in herds, and so they are highly attuned [...] and they are also great interpreters of what a relationship could be and what is happening in the here and now.

The healing process starts unfolding when the horses generate the learning experience by mirroring people's behaviour (PorterWenzlaff, 2007). The horse mirroring a person's behaviour therefore encourages client connection and a relationship based on trust and equality. Sessions may begin with tasks as simple as the client choosing a horse or the horse choosing the person and this process already contains meaning. Alistair explained why just brushing a horse could already be profound:

It's about bonding, it's about care, it's about nurturing. It's about all those things that maybe they don't have in their life. They get the opportunity to rebuild the bonds that were there in their childhood.
Participants thought that these authentic reflections were the foundation of the client's truthful self-discovery process. Rosemary confirmed:

There is no hiding, you can't really hide anything where you probably can in another dynamic where you can say "Well, that wasn't true." But you can't say that when the horse is standing there, reflecting back what's happening!

Horse-client interaction is achieved energetically, through clues or body language and the emphasis is always on relationship, stated all participants. People in abusive relationships may feel more comfortable with horses who are prey animals as the predator role is taken out of the interactive activity (Hamilton, 2011). The horse mirroring a person's behaviour therefore encourages client connection, shared meaning and a relationship based on equality (Brandt, 2004).

The practitioner as the knowledgeable guide working in the background holds space for transformational, long-lasting

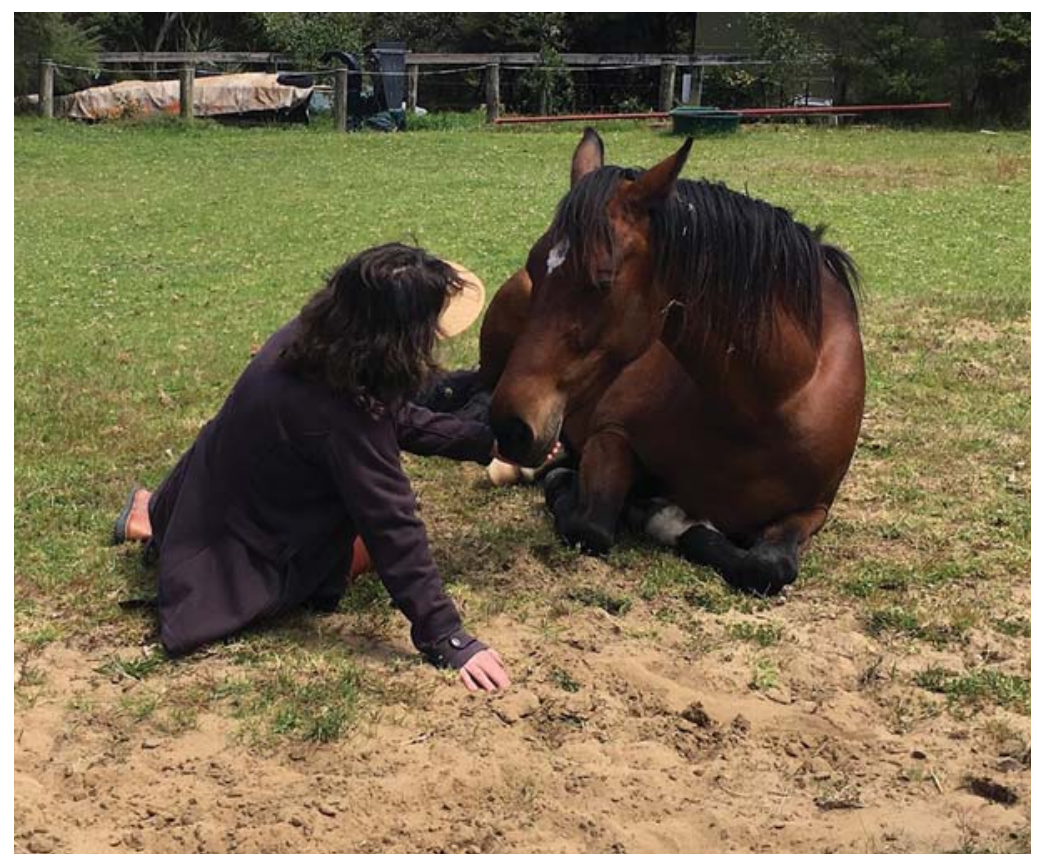

Let me tell you about this..... 
change, emphasising the importance of the therapeutic alliance (Burgon et al., 2018; Porter-Wenzlaff, 2007).

Themes that emerged during the interviews with four participants were introduced and explored. The following discussion will critically reflect and analyse the findings and compare them with those found in the literature.

\section{Discussion}

This research commenced with a curiosity about the therapeutic effects of the horse, practitioner and client triangle in EAI in relation to work with trauma and its compatibility with creative social work practice.

The findings of this study outlined the main themes that EAI practitioners find essential for effectiveness when working with clients who have experienced trauma or are facing emotional and psychological challenges. They unanimously pointed to the significance of a rural setting and the relationship based on respect and these findings confirmed results from international literature mentioned earlier. In the light of working with trauma and relevance of EAI, some other essential aspects emerged, which included:

- the provision of holding a safe space in order to create new learning and change;

- concepts of client inclusiveness;

- keeping horses in their natural environment; and

- providing choice and liberty for clients and horses.

These contributed significantly to what is perceived as a physically and emotionally safe environment.

Focusing on mutual trust, respect and clients' strengths resonates well with the main principles of effective social work practice (Clark \& Hoffler, 2014; Szczygiel, 2018; Yatchmenoff \& Sundborg, 2017). The findings highlighting alignment with humanistic values may promote easy implementation of EAI into social work practice. Participants claimed that, when working with clients with a history of complex trauma, EAI has particular potential to be utilised as complementary to traditional social work processes.

Underpinning values and frameworks, personal and professional experience, as well as techniques and knowledge, assist practitioners to accompany people on their transformative journey in a professional manner, thereby highlighting the importance of the practitioner's professional background. While the practitioner's willingness and non-directive influence have been documented as important, the practitioner's skilled guidance through the process and the ability to counterbalance the emergence of trauma reflects that EAI practice needs to be based on sound knowledge and expertise. A lesser known concept in this context is the illustration of a focus on mindfulness, the integration of silence and the present moment (Burgon et al., 2018; Hamilton, 2011; Klontz et. al., 2007). The connection and exchange between client and horse on a deeper level can also allow the experience of a spiritual journey if the person is open to it, adding an opportunity of meaning and purpose in clients' lives and utilising the experience with a horse as a metaphor for an issue a client may be struggling with, as Alistair explained:

It's never about the horse and it's never about the task. It's always about the response that comes with that. So, that's why the simplest, smallest things can have such a profound effect on people. [...] People want to move. People don't want to be stuck.

The shift of attention away from the person to the horse can be central to a person's 
authentic reflection and self-discovery process (Buck et al., 2017). Shifting away from the person is contrary to traditional therapeutic settings where clients may become repeatedly involved in discussions about their narratives of hurt or painful past events (Buck et al., 2017). Talking about traumatic events can enable some to regain mastery of their lives; however, as van der Kolk (2002) highlights, trauma must be seen as deeply connected to sensations and perceptions rather than to words. The traumatised individual may not necessarily find the words to verbally communicate these collections of feelings and bodily sensations, but when confronted, the process can easily lead to re-traumatisation and the avoidance of future talk-therapy (van der Kolk, 2002). Findings also suggest that EAI may also be useful for people who have not been reached by mainstream social work therapeutic processes.

The comforting warmth and presence of horses as well as the therapeutic relationship based on connection had been confirmed by previous literature and participants. Findings suggest that EAI brings, not only a practitioner who is non-judgmental to the practice, but also a benevolent horse who appears to be joining without prejudice and expectations, with the given choice of leaving in liberty at any moment. In this context, whatever happens can be used for reflection and growth and is guided by a client and supported by the knowledgeable EAI practitioner. This non-threatening alliance encourages clients to be authentic and to address issues they may want to attend to in order to live more fulfilling lives.

\section{Recommendations and limitations}

Although horses may have offered some sort of solace to humans for a long time, only recently EAI has been formalised and researched. Participants indicated that the reason might lie in the current trend of integrating a stronger focus on mindfulness and the present moment into professional practice. We wonder if connecting to the inner self in order to experience who we really are and then connecting with a horse from that authentic place may enable us to perceive our current issues in a different light and as a result, find out what is the core of the issue that has been perceived as a problem or an area of growth. It seems that a stronger utilisation of meditation and mindful concepts into social work practice might also be beneficial for social work clientele experiencing challenges.

EAI practice promotes authenticity and enables clients to step outside of performative roles and connect to themselves and others with grace and integrity. EAI has the potential to be utilised to a much greater extent in social work practice. Although the practitioner's interventions were based on knowledge, values and skills familiar to social workers, additional training in EAI will be required for its effective application in social work practice.

Currently, Oranga Tamariki (the statutory child protection and child welfare agency in Aotearoa New Zealand) recognises the benefit of this work by financially supporting children and youth to attend school holiday programmes offering opportunities to grow and develop new skills and abilities. However, it is not a panacea. It requires a willing participant open to an alternative approach, motivated and ready to explore how past trauma may have been embodied and how it may have impacted their current lives. Safety issues need to be addressed when clients are faced with a large and unpredictable animal as well as exploration of prior fears or allergies that may prevent people from being fully engaged. However we have witnessed people benefiting from this work from a distance-just observing what was going on in a paddock and later reflecting on it and linking it to their familiar patterns of being. In this modality, there is no coercion and participants are called to be responsible for their actions. This prevents accidents and ensures safety for horses and for humans equally. Cost is usually not a preventive 
factor as fees match usual therapeutic fees. The school holidays camps and team building activities are often more affordable than other programmes offering similar services.

\section{Future research}

The concept of EAI supports social work in various aspects and requires further exploration. Although it is relatively new field of research, a wealth of literature is available on the benefits of EAI. However, few studies provide information about the potential role social work practice could have in this field or the impact on practice with

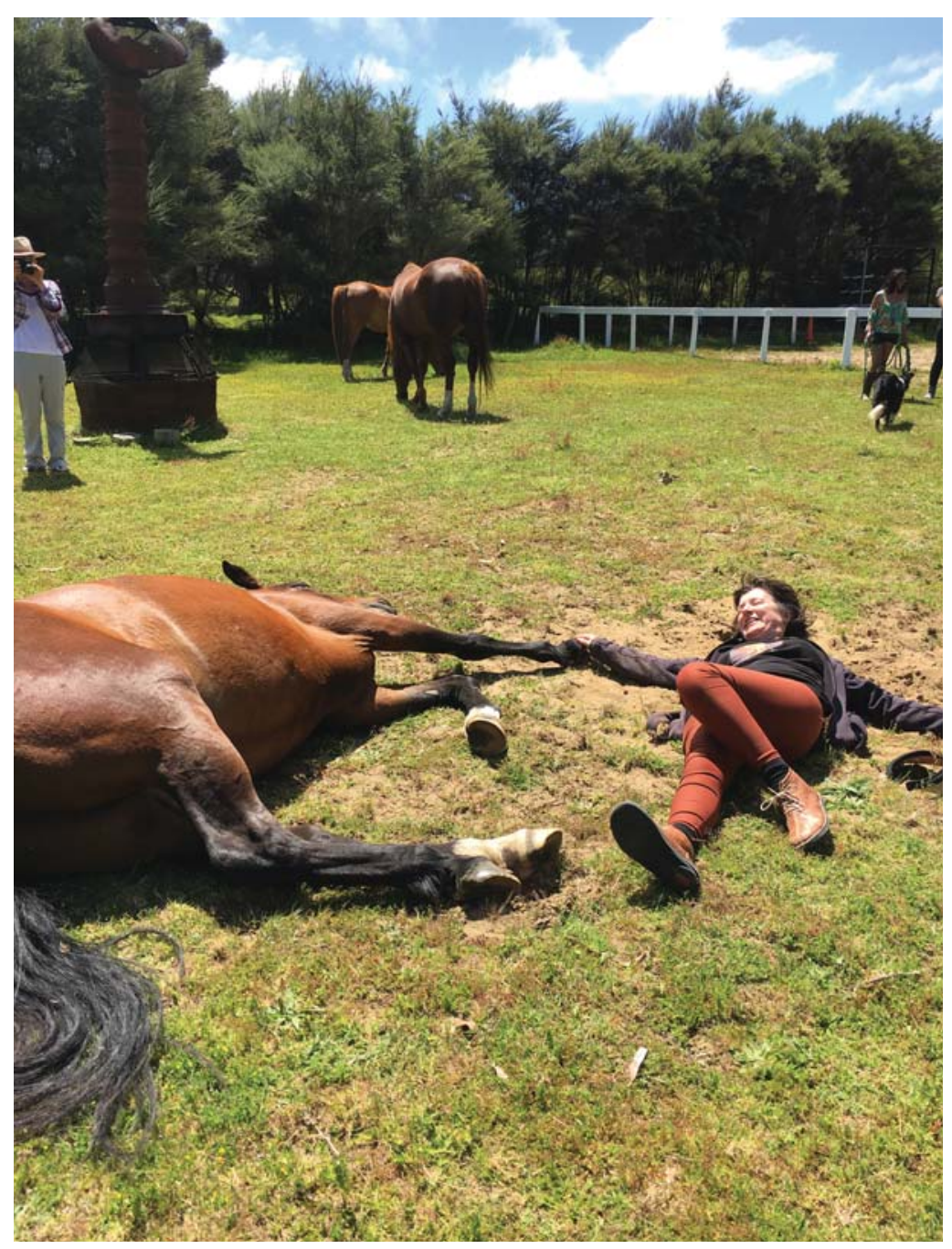

Trust and equality. social work clients, which is also connected to empowering projects that allow horses to collaborate on a voluntary, not forced, basis. Future research needs to investigate how EAI's therapeutic work could be utilised to a larger extent as an effective mental health and wellbeing tool by social services and how social work as a profession could integrate equine-assisted concepts. As a consequence, principles of EAI such as reflection, silent communication and equal power would reach a larger clientele, more social work clients could be referred to EAI practices and more social workers could be trained to become EAI practitioners.

Future investigations into funding issues, on how EAI could become a proven, costeffective treatment that can be used widely and be accessible for everybody who could benefit from having a learning experience with horses. Equine therapy establishments are not cheap to run and funding from the public sector would allow social work service users to utilise EAI. More research might have the potential to positively impact the view of EAI in the context of future trauma-informed care funded by the government, thereby multiplying opportunities for effective and affordable therapies for clients from all walks of life as well as for EAI-trained therapists offering their expertise. These may include more training opportunities, more field trips for school children and young people and more team-building activities where people from various walks of life can experience benefits from working with horses.

\section{Final comments}

Aotearoa New Zealand, with its vast open spaces and green pastures for large part of the year, enables people to keep horses at liberty in their paddocks. Dune Lakes Lodge offers holistic approaches and possibilities in a beautiful setting, including a herd of horses and highly trained practitioners with a background of theories and frameworks closely related to social work. Effects of EAI may not be immediately visible or 
felt, although sometimes they may feel like a lightning bolt as some participants described. Regardless, this research shows it is definitely worth further exploration and enabling as many social work clients as possible to explore this appreciative and mind-opening modality.

The next stage of the wider project at Dune Lakes Lodge is research with clients and their experiences of EAI with the focus on transformative learning from their perspective. This stage will be followed with the focus on horses, attempting to discover how reciprocity of interspecies communication plays out.

The emotional depth of a learning experience with a still mind and a horse that offers relationship and connection, enhances EAI's relevance for social work in the context of trauma-informed care. Treating horses with respect and allowing natural communication and behaviour to happen enables all participants to have an interspecies experience that has potential for emotional growth. EAI needs to be experienced widely and on a personal level, as Rosemary concluded:

Everyone should have a horse experience once in their life and that does not mean they go riding. It means to have a horse experience. A learning experience.

\section{Note}

The Ethics approval was granted with the reminder to include the following statement on all public documents:

"This project has been evaluated by peer review and judged to be low risk. Consequently, it has not been reviewed by one of the University's Human Ethics Committees. The researcher(s) named in this document are responsible for the ethical conduct of this research.

If you have any concerns about the conduct of this research that you want to raise with someone other than the researcher(s), please contact Associate Professor Tracy Riley, Acting Director (Research Ethics), email humanethics@massey.ac.nz."

Accepted 20 August 2020

Published 15 December 2020

\section{References}

Adams, C., Arratoon, C., Boucher, C., Cartier, G., Chalmers, D., Dell, C. A., ... Wuttunee, M. (2015). The helping horse: How equine assisted learning contributes to the wellbeing of First Nations Youth in treatment for volatile substance misuse. Human-Animal Interaction Bulletin, 1(1), 52-75.

Albright, B. (2018). Clinical trends: Consider the value of equine therapy. Behavioural Healthcare Executive, 1(4). Retrieved from https://www.psychcongress.com/article/ marketing/consider-value-equine-therapy

Anestis, M. D., Anestis, J. C., Zawilinski, L. L., Hopkins, T. A., \& Lilienfeld, S. O. (2014). Equine-related treatments for mental disorders lack empirical support: A systematic review of empirical investigations. Journal of Clinical Psychology, 70(12), 1115-1132. doi:10.1002/jclp.22113

ANZASW. (2019). Code of Ethics/Ngā Tikanga Matatika. Aotearoa New Zealand Association of Social Workers Te Rōpū Tauwhiro i Aotearoa. Retrieved from www. anzasw.nz

Brandt, K. (2004). A language of their own: An interactionist approach to human-horse communication. Society \& Animals, 12(4), 299-316.

Braun, V., \& Clarke, V. (2006). Using thematic analysis in psychology. Qualitative Research in Psychology, 3(2), 77-101.

Braun, V., \& Clarke, V. (2012). Thematic analysis. In H. Cooper (Ed.), APA Handbook of research methods in psychology: Research designs (pp. 57-71). American Psychological Association.

Buck, P. W., Bean, N., \& Marco, K. (2017). Equineassisted psychotherapy: An emerging trauma-informed intervention. Advances in Social Work, 18(1), 387-402. doi:10.18060/21310

Burgon, H., Gammage, D., \& Hebden, J. (2018). Hoofbeats and heartbeats: Equine-assisted therapy and learning with young people with psychosocial issues-theory and practice. Journal of Social Work Practice, 32(1), 3-16.

Carlsson, C. (2017). Equine-assisted social work counteracts self-stigmatisation in self-harming adolescents and facilitates a moment of silence. Journal of Social Work Practice, 32(1), 17-30.

Clark, E. J., \& Hoffler, E. F. (2014). Hope matters: The power of social work. National Association of Social Workers Press.

Donaghy, G. (2006). Equine assisted therapy. Mental Health Nursing, 26(4), 5.

Dune Lakes Lodge. (2015). Dune Lakes Lodge. Retrieved from https://dunelakeslodge.co.nz/

Dunlop, K., \& Tsantefski, M. (2017). A space of safety: Children's experience of equine-assisted group therapy. Child \& Family Social Work, 23, 1-24.

Frederick, K. E., Hatz, J. I., \& Lanning, B. (2015). Not just horsing around: The impact of equine-assisted learning on levels of hope and depression in at-risk adolescents. Community Mental Health, 51, 809-817.

Garden, E. R., \& Kabacoff, R. I. (2011). Evaluating research articles (3rd ed.). Sage Publications.

Hamilton, A. J. (2011). Zen mind, Zen horse: The science and spirituality of working with horses. Storey Publishing. 
Johansen, S.G., Wang, C.E.A., \& Binder, P-E. (2016). Facilitating change in a client's dysfunctional behavioural pattern with horse-aided psychotherapy: A case study. Counselling and Psychotherapy Research, 16(3), 222-231. https://doi.org/10.1002/capr.12078

Kern-Godal, A., Brenna, I. H., Arnevik, E. A., \& Ravndal, E. (2016). More than just a break from treatment: How substance use disorder patients experience the stable environment in horse-assisted therapy. Substance Abuse: Research and Treatment, 10, 99-108.

Klontz, B. T., Bivens, A., Leinart, D., \& Klontz, T. (2007). The effectiveness of equine-assisted experiential therapy: Results of an open clinical trial. Society and Animals, 15, 257-267.

Lee, P., \& Makela, C. (2018). Horse's roles in equineassisted psychotherapy: Perspectives of mental health practitioners. Journal of Psychology and Behavioural Science, 3(1), 78-95.

Merriam, S. (2002). Qualitative Research in Practice. Wiley.

Mueller, M. K., \& McCullough, L. (2017). Effects of equinefacilitated psychotherapy on post-traumatic stress symptoms in youth. Child Family Study, 26, 1164-1172.

Naste, T. M., Price, M., Karol, J., Martin, L., Murphy, K., Miguel, J., \& Spinazzola, J. (2017). Equine facilitated therapy for complex trauma (EFT-CT). Journal of Child \& Adolescents Trauma. doi:10.1007/s40653-017-0187-3

Porter-Wenzlaff, L. (2007). Finding their voice: Developing emotional, cognitive, and behavioural congruence in female abuse survivors through Equine Facilitated Therapy. Explore, 3(5).

Sanchez, C. T., Castro, F. V., Herrera, S. \& Juanez, J. C. (2014). Hormonal changes analysis by effects of horsesassisted therapy in the autistic population. Procedia Social and Behavioural Sciences, 132, 87-91.

Schroeder, K., \& Stroud, D (2015). Equine-facilitated group work for women survivors of interpersonal violence. The Journal for Specialists in Group work, 40(4), 365-386.

Shapiro, F. (2017). Eye movement desensitization and reprocessing (EMDR) therapy: Basic principles, protocols and procedures (3rd ed.). Guilford Press.

Smith, J. A., \& Osborn, M. (2003). Interpretative phenomenological analysis. In J. A. Smith (Ed.), Qualitative psychology: A practical guide to research methods (pp. 51-80). Sage Publications.

Sullivan, W. P. (2014). Borrowing hope. In E. J. Clark \& E. F. Hoffler (Eds.), Hope matters: The power of social work (pp. 138-142). NASW Press.

Szcygiel, P. (2018). On the value and meaning of traumainformed practice: Honouring safety, complexity, and relationship. Smith College Studies in Social Work, 88(2), 115-134.

Tolich, M., \& Davidson, M. (2011). An introduction into research methods: Getting started. Pearson.

Trevithick, P. (2008). Revisiting the knowledge base of social work: A framework for practice. British Journal of Social Work, 38, 1212-1237.

Trotter, K. S., Chandler, C.K., Goodwin-Bond, D., \& Casey, J. (2008). A comparative study of the efficacy of group equine assisted counselling with at-risk children and adolescents. Journal of Creativity in Mental Health, 3(3), 254-284.
Tuuvas, M., Carlsson, J., \& Norberg, J. (2017). A healing relationship: Clients' experiences of the long-term relational significance of the horse in horse-assisted psychotherapy. European Journal of Psychotherapy \& Counselling, 19(3), 307-328.

van der Kolk, B.A. (2002). Beyond the talking cure: Somatic experience and subcortical imprints in the treatment of trauma. In F. Shapiro (Ed.), EMDR as an integrative psychotherapy approach: Experts of diverse orientations explore the paradigm prism (vol vii, pp. 57-83). Washington DC: American Psychological Association.

Waite, C., \& Bourke, L. (2013). "It's different with a horse": Horses as a tool for engagement in a horse therapy program for marginalised young people. Youth Studies Australia, 22(4), 15-24.

Wamser-Nanney, R., \& Vandenberg, B. R. (2013). Empirical support for the definition of a complex trauma event in children and adolescents. Journal of Traumatic Stress, 26(6), 671-678. doi:10.1002/jts.21857

Yatchmenoff, D. K., \& Sundborg, S. A. (2017). Implementing trauma-informed care: Recommendations on the process. Advances in Social Work, 18(1), 167-185. 